\title{
NOVO CPC E A ATUAÇÃO DOS PROCURADORES DO MUNICÍPIO
}

\section{THE NEW CIVIL PROCEDURE CODE AND THE CITY ATTORNEYS}

Eduardo de Souza Floriano

Procurador do Município de Juiz de Fora/MG, formado em Direito pela Universidade Federal de Juiz de Fora, Especialista em Direito Público pelo Centro Universitário Newton Paiva, Especialista em Direito do

Consumidor pela Universidade Federal de Juiz de Fora, Professor Convidado da Escola Estadual de Defesa do Consumidor, vinculada ao Ministério Público do Estado de Minas Gerais.

Resumo: O presente estudo aborda o novo código de processo civil especificamente no que toca à atuação dos Procuradores Municipais. Inicia-se com uma contextualização do novo código, passando por uma análise dos principais institutos jurídicos criados ou reformulados e culminando com uma análise mais detida do trabalhio realizado pelos procuradores municipais.

Palavras-chave: Novo CPC - Advocacia Pública Municipal - questões legais municipais

\begin{abstract}
This study is about the new civil procedure code specifically regarding the role of City Attorneys. It begins with a contextualization of new code, then it analyses some legal institutions created or reformulated by the code and then it has a more detailed analysis of the work done by city attorneys.
\end{abstract}

Keywords: New Civil Procedure Code - City Attorney - city legal matters. 
1. Introdução - 2. O novo CPC - visão geral - 3. A Fazenda Pública Municipal em Juízo - 4. As prerrogativas dos Municípios e dos Procuradores Municipais em juízo - 5. Conclusão - 6. Notas - 7. Referências bibliográficas.

\section{INTRODUÇÃO}

Há tempos os profissionais do direito conclamavam por uma profunda modificação da legislação processual brasileira de forma a dar maior dinamismo ao processo civil e, concomitantemente, garantir maior segurança jurídica. Os processos judiciais se multiplicam pelo país e, muitas vezes, se arrastam pelos Tribunais. Mesmo com a inserção, na Constituição Federal, do direito fundamental dos cidadãos à “razoável duração dos processos", esse preceito constitucional não vem sendo cumprido pelo Poder Judiciário.

Diante deste cenário, o Senado Federal nomeou em setembro de 2009 uma comissão de notáveis juristas para apresentar uma minuta de projeto de revisão da legislação adjetiva civil. Após árduo trabalho foi apresentado ao Congresso Nacional o "Projeto de Lei do Senado 166/2010" que tratava da aprovação do Novo Código do Processo Civil (NCPC). Após anos de discussão e com diversas emendas à proposta original, o NCPC foi aprovado em ambas as casas legislativas e sancionado pela Presidente Dilma.

Publicada em 16 de março de 2015, o NCPC (Lei Ordinária Federal n. ${ }^{\circ}$ 13.105/15) traz inúmeras e relevantes mudanças em relação ao código vigente. Previsto para entrar em vigor em 16 de março de 2016 o NCPC tem como escopo principal, nas palavras do Ministro do STF e presidente da Comissão de juristas, Luiz Fux, "dar maior celeridade ao julgamento de ações cíveis".

Dentre as diversas inovações e mudanças trazidas pelo NCPC, estão algumas que afetarão diretamente a atuação da Fazenda Pública em juízo, exigindo dos Advogados Públicos, conhecimento e capacitação para esse novo 
Revista da ESDM - 2016 - V. 2 - n. ${ }^{\circ} 3$

marco do ordenamento jurídico pátrio.

O presente estudo visa auxiliar parcela dessa categoria (advocacia pública municipal), trazendo breves apontamentos sobre os principais pontos e mudanças trazidas pelo NCPC que impactarão na atuação em defesa dos Municípios brasileiros.

Não se busca, por certo, exaurir o tema, mas sim apresentar os principais dispositivos que afetam diretamente a atuação dos procuradores municipais no exercício de suas funções.

\section{O NOVO CPC - VISÃO GERAL}

Ao iniciarmos a leitura do NCPC uma primeira inovação salta aos olhos. O art. $1 .^{\circ}$ dispõe a preocupação do legislador na subordinação das normas do CPC aos valores e as normas fundamentais esculpidas na Constituição da República Federativa do Brasil. Trata-se de evolução semelhante à observada na elaboração do Código Civil de 2002, privilegiando uma visão neoconstitucionalista.

Outra inovação foi a regulamentação das chamadas tutelas de urgência e de evidência que substituíram o regime das cautelares.

A simplicidade dos procedimentos e a celeridade são, também, marcos do NCPC, bem como a adoção de medidas de redução dos recursos, da prevalência das decisões dos Tribunais Superiores visando conferir maior segurança jurídica e estabilidade ao sistema jurídico e da criação do Incidente de Resolução de Demandas Repetitivas.

Por fim, cita-se a visão conciliadora do NCPC. Medidas visando a autocomposição dos litígios e o uso da mediação foram incentivadas pelo novo código.

Em linhas gerais esses são os fundamentos basilares da nova norma processual civil. 


\section{A FAZENDA PÚBLICA MUNICIPAL EM JUÍZO}

Assim como expressamente previsto no CPC/73, o novo código mantém a sistemática de representação judicial do Município na pessoa do seu Prefeito ou Procurador. Infelizmente, o legislador pecou pela falta de técnica. Como já decidiu reiteradamente o $\mathrm{STF}^{1}$ a representação judicial dos entes estatais compete, exclusivamente, aos integrantes da Advocacia Pública, admitidos mediante concurso público, inclusive em relação aos Municípios. Ao repetir a redação anterior, dá-se uma falsa percepção de que o Prefeito pode, livremente, designar aquele que representará o Município em Juízo.

Prosseguindo, o NCPC ao regular a representação judicial das autarquias e fundações de direito público, dispõe que a representação judicial caberá a "quem a lei do ente federado designar". Novamente, a redação peca pela redação imprecisa. Conforme já dito anteriormente, a representação judicial dos entes públicos deve ser realizada de forma privativa por servidores da carreira de advogado público. O que se vê na prática é que ou a representação compete ao órgão jurídico central ou a órgão jurídico próprio da autarquia ou fundação, com as mesmas características do órgão central e, tecnicamente subordinado a este. Para ilustrar o raciocínio podemos citar, no âmbito da União, a representação judicial das autarquias federais pela Procuradoria Geral Federal, estruturada por servidores de carreira dentro do âmbito da Advocacia Geral da União.

Todavia, seguindo na leitura do NCPC, vimos que o art. 182, complementando a norma do art. 75, explicita ser a representação judicial dos entes públicos exclusiva dos membros da advocacia pública, sendo esta norma mais coerente com a regra esculpida na constituição federal art. 132. ${ }^{2 e 3}$

Vimos, portanto, que embora uma leitura apressada do texto do art. 75 do NCPC possa levar à interpretação de que a representação dos Municípios em Juízo cabe aos procuradores ou ao Prefeito Municipal, uma interpretação sistemática (art. 75 c/c art. 182) e fincada nos princípios constitu- 
Revista da ESDM - 2016 - V. 2 - n. ${ }^{\circ} 3$

cionais pertinentes permite concluir que compete, com exclusividade, à advocacia pública, a representação dos Municípios em juízo.

\section{AS PRERROGATIVAS DOS MUNICÍPIOS E DOS PROCURADO- RES MUNICIPAIS EM JUÍZO}

A atuação da fazenda pública em juízo ganhou destaque no NCPC, mediante a criação de um título específico destinado à Advocacia Pública (Livro III - Dos Sujeitos do Processo - Título VI - Da Advocacia Pública), bem como a determinação, em regras esparsas, de diversas prerrogativas dos entes públicos e/ou seus procuradores.

Primeiro destaque refere-se à norma trazida pelo art. 182 do NCPC que, como dito, em obediência aos princípios trazidos pelos arts. 131 e 132 da Constituição Federal, dispõe que incumbe à Advocacia Pública, na forma da lei, defender os interesses públicos da União, Estados e Municípios, por meio de representação judicial em todos os âmbitos federativos, das pessoas jurídicas de direito público que integram a administração direta e indireta.

Nota-se, em razão da cristalina redação do artigo, que a função de representação judicial de entes públicos, inclusive da administração indireta, compete, de forma exclusiva, à Advocacia Pública.

Prosseguindo, dispõe o art. 183 que os entes públicos possuem prazo em dobro para todas as suas manifestações processuais, cuja contagem dar-se-á a partir da intimação pessoal dos autos. Verifica-se, neste particular, que o legislador, acertadamente, estendeu a toda a advocacia pública, prerrogativas que antes eram apenas conferidas integralmente ao Ministério Público, à Defensoria Pública e às carreiras da AGU. ${ }^{4}$

Cabe ressaltar que, embora tenha ocorrido uma diminuição no prazo para contestar (que era em quádruplo para os entes públicos) o NCPC adotou uma nova sistemática de contagem dos prazos em dias úteis (art. 217) além 
da contagem do prazo de contestação iniciar-se, via de regra, apenas após o prazo de audiência de conciliação (art. $335^{5}$ ), o que, de certa forma, compensará a diminuição do prazo de contestação permitindo ao advogado público mais tempo para obtenção dos elementos necessários para a defesa do ente público em juízo. ${ }^{6}$

Ademais, visando esclarecimento quanto à prerrogativa da intimação pessoal, o $\$ 1^{\circ}$ do art. 183 dispôs que esta ocorrerá não só por carga dos autos, mas também por remessa ou por meio eletrônico.

Embora as disposições do citado título VI sejam breves, podemos observar, ao longo dos mais de mil artigos que compõe o NCPC, diversas outras prerrogativas da fazenda pública ou dos advogados públicos quando em atuando em juízo, as quais serão sinteticamente expostas a seguir.

\subsection{RECONHECIMENTO DA IMPOSSIBILIDADE DO REPRESEN- TANTE JUDICIAL DA PARTE DE SER COMPELIDO A CUMPRIR DE- CISÃO JUDICIAL}

O art. $77, \$ 8 .^{\circ}$ do NCPC, firmando entendimento já sedimentado na doutrina e jurisprudência, dispõe que o representante judicial da parte não pode ser compelido a cumprir a decisão judicial.

Embora a regra não seja direcionada especificamente aos Advogados Públicos, essa situação era observada com mais frequência no âmbito das ações envolvendo os entes estatais. Isso porque diversos magistrados, no afã de proteger o direito do cidadão, vislumbrando a dificuldade de atingir o gestor público, muitas vezes enxergava no membro da advocacia pública como alvo predileto para a ordem judicial.

Ocorre que essa posição nunca encontrou amparo legal e doutrinário conforme se observa nas decisões dos tribunais, podendo citar o seguinte julgado do TRF1: 
Revista da ESDM - 2016 - V. 2 - n $\circ 3$

PROCESSUAL. PENAL. HABEAS CORPUS. AMEAÇA DE PRISÃO POR DESCUMPRIMENTO DE DECISÃO JUDICIAL. MEMBRO DA ADVOCACIA GERAL DA UNIÃO. ORDEM CONCEDIDA.

1. Hipótese em que o impetrante e paciente adotou providências para que se fizesse cumprir a decisão judicial.

2. O membro da Advocacia Geral da União detém atribuições de representação judicial e de consultoria, não podendo, portanto, ser compelido a agir fora dos limites de suas atribuições.

3. Habeas corpus concedido. (TRF1, HC 2003.01.00. 029515-5/MT, Rel. Desembargador Federal I'talo Fioravanti Sabo Mendes, Quarta Turma,DJ p.63 de 12/02/2004)

Sepultando a questão, Conselho Nacional de Justiça - CNJ decidiu, nos autos do Pedido de Providência n. ${ }^{\circ}$ 749-61.2011.2.00.0000/MG, expedir comunicado aos Presidentes e Corregedores dos Tribunais, informando-os de que não se pode exigir do Advogado Público que se responsabilize pelos atos do destinatário de decisão judicial:

O Conselho, por maioria, decidiu oficiar aos Presidentes e Corregedores dos Tribunais para que transmitam aos magistrados a preocupação quanto a eventual punição de patronos de agentes da administração pública, nos termos do voto do Relator. Vencido o Conselheiro Vasi Werner, que não conhecia do pedido. Presidiu o julgamento o Ministro Cezar Peluso. Plenário, 30 de agosto de 2011. 
Do voto do relator, colhe-se o seguinte trecho:

Outrossim, do exercício regular de sua profissão não segue a responsabilidade do advogado pelo descumprimento de comandos judiciais nem que ele deixou de comunicá-los ao seu destinatário. O advogado público é mero coadjuvante nesse cenário, a quem incumbe, é verdade, o dever de comunicar a decisão judicial ao responsável por seu cumprimento, e não ele próprio efetivá-la. Ele não tem competência para cumprir as decisões judiciais e não é destinatário dos comandos judiciais porque não é gestor encarregado dos bens e serviços públicos objeto das ações judiciais. Ao advogado público compete levar o conteúdo da decisão judicial ao conhecimento do agente público destinatário do comando judicial, para que o responsável por seu cumprimento efetive-o.

Ademais, importa esclarecer que não há relação hierárquica entre o advogado público e os agentes públicos responsáveis pela efetivação dos comandos jurisdicionais. Não há subordinação entre eles, razão pela qual não se pode exigir do advogado público que se responsabilize pelos atos do destinatário da decisão.

\subsection{DESPESAS AO FIM (ART. 91)}

Embora não dirigida ao Procurador Municipal, destaca-se a prerrogativa dirigida aos entes públicos de pagamento dos atos processuais, requeridos pelos mesmo públicos, somente ao fim do processo, pela parte vencida, na forma do art. 91. Todavia, o referido dispositivo revela uma única exce- 
Revista da ESDM - 2016 - V. 2 - n. ${ }^{\circ} 3$

ção relativa às perícias requeridas pela Fazenda Pública a qual poderá ser feita por entidade pública ou, havendo previsão orçamentária, ter o valor adiantado por aquele que requereu a prova. ${ }^{7}$

\subsection{INAPLICABILIDADE DO RECESSO FORENSE AOS ADVOGA- DOS PÚBLICOS}

O Novo CPC regulamentou as férias forenses aos advogados. Conforme disposto no art. 220 fica suspenso o curso dos prazos processuais nos dias compreendidos entre 20 de dezembro e 20 de janeiro, inclusive. Todavia, a referida regra não é aplicável aos membros da magistratura, aos auxiliares do judiciário e aos membros do Ministério Público aos Defensores Públicos e aos Advogados Públicos.

Por certo é acertada a norma já que o recesso forense é dirigido aos advogados privados autônomos, que não possuem "férias" para gozar diferentemente dos servidores públicos ora excepcionados, que tem, por lei, direito às férias individuais, sendo devidamente substituídos por outro servidor da carreira durante suas ausências.

\subsection{IMPOSSIBILIDADE DE APLICAÇÃO DE MULTA POR ATOS ATENTATÓRIOS À JUSTIÇA}

Diferentemente dos advogados privados, não poderá o magistrado aplicar a penalidade de multa prevista no art. $77,2{ }^{\circ}$ do NCPC, aos advogados públicos, em razão da ocorrência de atos atentatórios à justiça. Todavia, o Magistrado deverá oficiar o respectivo órgão de classe ou corregedoria para apuração de eventual responsabilidade disciplinar.

4.5 CITAÇÃO E INTIMAÇÃO OCORRE PERANTE O ÓRGÃO DA ADVOCACIA PÚBLICA 
Outra regra de grande valia para o perfeito funcionamento dos órgãos da advocacia pública é a previsão expressa de que a citação e intimação dos entes públicos, seja administração direta ou indireta, deverão acontecer perante o Órgão da Advocacia Pública.

A regra prevista pelos arts. $242, \$ 3 .^{\circ}$ e $269, \$ 3 .^{\circ}$ do NCPC destina-se à dar celeridade às manifestações da advocacia pública.

\subsection{ESTIPULAÇÃO DE HONORÁRIOS ADVOCATÍCIOS CONTRA A FAZENDA PÚBLICA}

Como é curial, os recursos da Fazenda pública são provenientes dos tributos arrecadados pelos entes públicos e da exploração de seus bens e serviços. Diante desta realidade, o legislador decidiu por adotar critérios diferenciados para a estipulação, pelo Magistrado, dos honorários de sucumbência contra a Fazenda Pública, visando a racionalização dos gastos públicos, que, em última análise é financiada pela população em geral.

Em um primeiro momento (art. 85, \$3. ${ }^{\circ}$ ) o NCPC prevê além dos critérios clássicos (I - o grau de zelo do profissional; II - o lugar de prestação do serviço; III - a natureza e a importância da causa; IV - o trabalho realizado pelo advogado e o tempo exigido para o seu serviço.) para determinação do valor dos honorários, um limitação percentual do valor de acordo com o valor da condenação ou do proveito econômico obtido, sendo entre: A) $10 \%$ e $20 \%$ até 200 Salários Mínimos (SM), B) 8\% e 10\% entre 200 e 2.000 SM, C) $5 \%$ e $8 \%$ entre 2.000 e 20.000 SM, D) $3 \%$ e $5 \%$ entre 20.000 e 100.000 SM e, E) $1 \%$ e $3 \%$ acima de $100.000 \mathrm{SM}$.

Ressalte-se que a definição dos referidos percentuais deverão ser aplicados pelo juiz quando for líquida a sentença. Quando ilíquida, deverá ser definida no momento da liquidação da sentença.

Prosseguindo, o $\$ 5 .^{\circ}$ do citado art. 85 determina que a aplicação dos per- 
Revista da ESDM - 2016 - V. 2 - n. ${ }^{\circ} 3$

centuais ocorre em cascata, isto é, a fixação do percentual de honorários deve observar a faixa inicial e, naquilo que a exceder, a faixa subsequente, e assim sucessivamente.

Por fim, o $\$ 7 .^{\circ}$ dispõe que "Não serão devidos honorários no cumprimento de sentença contra a Fazenda Pública que enseje expedição de precatório, desde que não tenha sido impugnada."

\subsection{OS HONORÁRIOS DE SUCUMBÊNCIA COMO DIREITO DO AD- VOGADO PÚBLICO}

Em boa hora o legislador federal resolveu acabar com a celeuma acerca do direito do Advogado Público à percepção dos honorários de sucumbência. Embora diversos Municípios e Estados tenham leis próprias reconhecendo esse direito, esta posição não era unânime criando uma injustificada diferenciação das diversas carreiras que compõem a advocacia pública.

A regra do art. 85, \$19 do NCPC prevê que "Art. 85. A sentença condenará o vencido a pagar honorários ao advogado do vencedor. (...) \$19 Os advogados públicos perceberão honorários de sucumbência, nos termos da lei."

A cristalina redação do art. 85 impõe que o vencido no processo judicial deverá pagar, ao advogado do vencedor, honorários (de sucumbência). Previsto desde o CPC de 1939, o instituto dos honorários sucumbenciais sofreu uma evolução interpretativa até culminar na tese atual de que tal verba é um direito do advogado (seja público ou privado) consubstanciando-se, inclusive, uma verba autônoma (em relação à condenação) e de caráter alimentar (Sumula Vinculante 47 STF) para o advogado.

Na seara pública muito se discutiu sobre a natureza dos honorários quando o vencedor é ente público. Parte da doutrina e dos Tribunais entendiam tratar-se de verba pública outros de verba privada (devida aos advogados públicos). 
A pacificação do tema com a publicação do NCPC, demonstra que outro não poderia ser entendimento sobre a questão, já que uma detida análise do instituto aponta, com clareza para a natureza privada da verba. Isto porque, uma avaliação do tema sob o enfoque do direito financeiro-orçamentário e do histórico do instituto (honorários de sucumbência) permitem uma serena conclusão quanto ao tema. Primeiro, como dito, a evolução histórica do instituto culminou no entendimento dos honorários como um direito autônomo do advogado. Ademais, sob o enfoque do direito financeiro e orçamentário temos que os honorários não decorrem de uma fonte ordinária de receita pública.

As receitas públicas podem ser classificadas, na forma da lei federal $n .^{\circ}$ 4.320/64, como orçamentárias e extra-orçamentárias. ${ }^{8}$ As receitas orçamentárias são decorrentes da ação Estatal e se dividem em RECEITAS CORRENTES (1 Receita Tributária, 2 Receita de Contribuições, 3 Receita Patrimonial, 4 Receita Agropecuária, 5 Receita Industrial, 6 Receita de Serviços, 7 Transferência Corrente, 8 Outras Receitas Correntes) e RECEITAS DE CAPITAL (1 Operações de Crédito, 2 Alienação de Bens, 3 Amortização de Empréstimos, 4 Transferências de Capital e 5 Outras Receitas de Capital).

Uma análise detida das modalidades de receitas públicas permite concluir, serenamente, que a verba oriunda de derrota de um litigante em juízo não se configura dentro das classificações de receita pública, já que não deriva da atividade Estatal nem é voltada para ao financiamento das atividades estatais. Pelo contrário, decorre exclusivamente da natureza da profissão exercida pelo membro da advocacia pública (não pelo exercício da sua função pública mas da natureza da sua profissão). A verba é devida, como dita ao ADVOGADO do vencedor, conforme construção legal e histórica.

Não sendo, portanto, receita pública, é devida também ao advogado público que, mesmo no exercício da sua função pública, não perde as prerrogativas inerentes ao sua profissão. 
Revista da ESDM - 2016 - V. 2 - n. ${ }^{\circ} 3$

Ressalte-se que, para fins de facilitação ou otimização do sistema de arrecadação das condenações judiciais muitos entes públicos acabam por arrecadar os honorários advocatícios, dando ao mesmo, contudo o tratamento de RECEITA EXTRAORÇAMENTÁRIA, já que pertencentes a terceiros (advogados).

Assim, nota-se a grande importância da regulamentação do tema pelo NCPC pacificando o entendimento sobre o tema e afastando os conflitos outrora existentes sobre a natureza da verba e a destinação dos honorários aos membros da advocacia pública.

\subsection{DA REMESSA NECESSÁRIA}

Assim como previsto no CPC anda vigente, o Art. 496 do NCPC prevê a sujeição das sentenças (preferida contra entes públicos ou que julguem procedentes embargos à execução fiscal), não produzindo efeito senão depois de confirmada pelo Tribunal.

Todavia, a norma prevê exceção à regra baseada em critério financeiro, dispondo que não haverá remessa necessária quando a condenação ou o proveito econômico obtido na causa for de valor certo e líquido inferior a mil salários mínimos em relação à união e suas entidades, quinhentos salários mínimos em relação aos Estados e suas entidades e 100 salários mínimos em relação aos municípios e suas entidades.

Outras exceções são as hipóteses de sentenças fundadas em súmulas de tribunais superiores em recursos julgados na sistemática dos recursos repetitivos, em entendimento firmado em incidente de resolução de demandas repetitivas ou de assunção de competência e, por fim, e, em entendimento coincidente com orientação vinculante firmada no âmbito administrativo do próprio ente público, consolidada em manifestação, parecer ou súmula administrativa. 


\subsection{OBRIGAÇÃO DE CADASTRO PARA RECEBIMENTO DE CITA- ÇÕES E INTIMAÇÕES POR MEIO ELETRÔNICO}

Atento à universalização dos processos eletrônicos, e visando a efetividade e celeridade do tramite processual, o NCPC dispôs em seu art. 1.050 que o Município e a Advocacia Pública deverão se cadastrar perante a administração do tribunal no qual atuem, no prazo de 30 dias contados da sua vigência, para fins de recebimento de citações e intimações eletrônicas na forma do disposto nos arts. $246, \S 2 .^{\circ}$, e 270 , parágrafo único.

\subsection{RESTRIÇÃO ÀS REGRAS DE CONCESSÃO DA TUTELA ANTE- CIPADA FACE A FAZENDA PÚBLICA}

A nova lei adjetiva civil prevê, expressamente, no art. 1.059, a aplicação das normas previstas nos arts. $1 .^{\circ}$ a $4 .^{\circ}$ da Lei n. ${ }^{\circ} 8.437$, de 30 de junho de 1992 (que dispõe sobre a concessão de medidas cautelares contra atos do Poder Público e dá outras providências.), e no art. $7 .^{\circ}, \S 2 .^{\circ}$, da Lei $n .^{\circ}$ 12.016, de 7 de agosto de 2009, (que regulamenta o Mandado de Segurança) nas hipóteses de requerimento de tutela provisória contra a Fazenda Pública.

\section{CONCLUSÃO}

Conforme se pode observar ao longo do presente estudo, o novo CPC manteve diversas das prerrogativas inerentes à atuação da Fazenda Pública em juízo, trouxe novas regras em virtude da universalização do processo judicial eletrônico, mas principalmente, ressaltou a relevância da advocacia pública no contexto dos Entes Públicos. A criação de um capítulo à parte, exclusivamente destinado para regulamentar a atuação da Advocacia Pública, demonstra a relevância que o legislador distinguiu à carreira e a importân- 
Revista da ESDM - 2016 - V. 2 - n. ${ }^{\circ} 3$

cia da atuação dos seus membros na defesa dos bens e interesses públicos.

Outro ponto de destaque no NCPC foi o reconhecimento do direito dos advogados públicos aos honorários de sucumbência, pacificando, assim, uma antiga discussão acerca da natureza jurídica e titularidade desta verba.

Diante deste quadro nota-se que a publicação do NCPC trata-se de um marco para o reconhecimento da relevância da Advocacia Pública na administração da justiça e sua imprescindibilidade na defesa da legalidade e do interesse público.

\section{NOTAS}

1. ADI 4.261, Rel. Min. Ayres Britto, julgamento em 2-8-2010, Plenário, DJE de 20-8-2010. No mesmo sentido: ADI 4.843-MC, rel. min. Celso de Mello, decisão monocrática, julgamento em 19-12-2013, DJE de 3-2-2014; ADI 881-MC, Rel. Min. Celso de Mello, julgamento em 2-8-1993, Plenário, DJ de 25-4-1997.

2. Em que pese o Município não conste no texto do art. 132 da CF/88 o TJES assim decidiu nos autos da ação direta de inconstitucionalidade 1001200001654: "EMENTA: AÇÃO DIRETA DE INCONSTITUCIONALIDADE - PRELIMINAR DE INÉPCIA DA INICIAL - REJEITADA - MÉRITO - MUNICÍPIO DE LINHARES - ARTIGO 329 E ANEXO II DA LEI N $^{\circ}$ 2.560/2005 - CARGO DE PROCURADOR MUNICIPAL - FUNÇÃO COMISSIONADA - IMPOSSIBILIDADE - CARREIRA ACESSÍVEL SOMENTE POR CONCURSO PÚBLICO - PREVISÃO CONSTITUCIONAL - ARTIGO 132 DA CARTA MAGNA E 122 DA CONSTITUIÇÃO DO ESTADO DO ESPIRITO SANTO - NECESSÁRIA OBSERVÂNCIA PELA LEI ORGÂNICA MUNICIPAL - PRINCÍPIO DA SIMETRIA . (...)

(...) 2 - Apesar da exigência constitucional do concurso público, a ausência de uma abordagem especifica da Constituição Federal acerca da carreira jurídica municipal fez surgir uma comum e reiterada presença de cargos comissionados nesses setores, contudo, por meio de uma análise principiológica e constitucional, percebe-se que a estruturação das carreiras jurídicas municipais deve efetivar-se de forma simétrica às carreiras jurídicas da união e dos estados federados, sob pena, ao se adotar caminho diverso, de vir a incorrer em uma flagrante ofensa a diversos princípios constitucionais regentes da atividade administrativa e da Constituição Federal." 
3. Tramita no Congresso Nacional a PEC 17 a qual, de forma expressa, inclui as procuradorias Municipais na redação do art. 132 da Constituição Federal. A referida PEC já foi aprovada na Câmara dos Deputados, faltando, apenas, a aprovação no Senado.

4. A intimação pessoal aos Advogados Públicos de todas as esferas somente era prevista nas execuções fiscais (lei 6.830/80, art. 25). Nos demais procedimentos, apenas as diversas carreiras da Advocacia Pública da União possuíam a prerrogativa de intimação pessoal (vide: 1- Lei complementar n. ${ }^{\circ} 73 / 1993$, art. 38; 2- Lei 9.028/1995, art. 6. ${ }^{\circ}$; 3- Lei 10.910/2004, art. 17 e 4- Lei 11.033/2004, art. 20).

5. Art. 335. O réu poderá oferecer contestação, por petição, no prazo de 15 (quinze) dias, cujo termo inicial será a data:

I - da audiência de conciliação ou de mediação, ou da última sessão de conciliação, quando qualquer parte não comparecer ou, comparecendo, não houver autocomposição;

II - do protocolo do pedido de cancelamento da audiência de conciliação ou de mediação apresentado pelo réu, quando ocorrer a hipótese do art. $334, \S 4 .^{\circ}$, inciso I;

III - prevista no art. 231, de acordo com o modo como foi feita a citação, nos demais casos.

6. Embora a prerrogativa de prazos estendidos para a atuação dos entes públicos em juízo venha sendo objeto de muitas críticas ao longo do tempo, é cediço que, diferente da esfera privada, a obtenção de dados, informações e elementos fáticos para embasamento das manifestações da advocacia é dificultosa, tendo em vista toda a burocracia que envolve a atividade estatal, o que, por si só, justifica esse "benefício processual".

7. (art. 91, 2. ${ }^{\circ}$ ) Não havendo previsão orçamentária no exercício financeiro para adiantamento dos honorários periciais, eles serão pagos no exercício seguinte ou ao final, pelo vencido, caso o processo se encerre antes do adiantamento a ser feito pelo ente público.

8. Os ingressos orçamentários são aqueles pertencentes ao ente público arrecadados exclusivamente para aplicação em programas e ações governamentais. Estes ingressos são denominados Receita Pública.

Os ingressos extra-orçamentários são aqueles pertencentes a terceiros arrecadados pelo ente público exclusivamente para fazer face às exigências contratuais pactuadas para posterior devolução. Estes ingressos são denominados recursos de terceiros. 
Revista da ESDM - 2016 - V. 2 - n. ${ }^{\circ} 3$

\section{REFERÊNCIAS BIBLIOGRÁFICAS}

Floriano, E. S. A Fazenda Pública No Novo Código de Processo Civil. Revista do Tribunal Regional Federal 1. Região, v. 5, p. 25-39, 2012.

FLORIANO, E. S. Sistema Municipal de Defesa do Consumidor - Criação e Regulamentação Legal. Revista da Procuradoria-Geral do Município de Juiz de Fora-RPGMJF, v. 1,p. 79-96, 2012.

FLORIANO, E. S. A necessidade de reformulação do Sistema Nacional De Trânsito. Revista Eletrônica Jus Vigilantibus, v. 1, p. 1-1,2009.

FLORIANO, E. S. Ainda há tempo para a cobrança das perdas da poupança com o Plano Verão. Jus Navigandi (Teresina), v. 2016, p. 1-1, 2009.

FLORIANO, E. S. A nova Lei do Mandado de Segurança. Comentários e quadro comparativo (Lei n. ${ }^{\circ} 12.016 / 09$ x Lei n. ${ }^{\circ} 1.533 / 51$ ). Revista do Tribunal Regional Federal 1. Região, v. 10, p. 71-93, 2009.

FLORIANO, E. S. A Constituição Federal permite a condução de veículo automotor, sob influência de álcool, sem que o condutor sofra qualquer tipo de molestação pela Autoridade Policial?. Jus Navigandi (Teresina), v. 1976, p. 1-1, 2008.

FLORIANO, E. S. Processo administrativo de trânsito cassação e suspensão do direito de dirigir. Revista Eletrônica Jus Vigilantibus, v. 1, p. 1-1, 2008.

FLORIANO, E. S. Eleições 2008: passo a passo da candidatura a vereador. Jus Navigandi, v. 1808 , p. 1-1, 2008.

FLORIANO, E. S. Gastos ilimitados para as eleições municipais de 2008. Revista Eletrônica Jus Vigilantibus, v. 1, p. 1-1, 2008.

FLORIANO, E. S. Calendário Eleitoral para as eleições municipais de 2008. Revista Eletrônica Jus Vigilantibus, v. 1, p. 1-1, 2008.

FLORIANO, E. S. Breves comentários acerca da Portaria-Conjunta no 119/2008 do TJMG que institui o Diário Judiciário Eletrônico e dispõe sobre a contagem dos prazos processuais. Revista Eletrônica Jus Vigilantibus, v. 1, p. 1-1, 2008.

FLORIANO, E. S. Comentários à Lei das Comissões de Conciliação Prévia. Revista Eletrônica Jus Vigilantibus, v. 1, p. 1-1, 2007.

FLORIANO, E. S. Prazo prescricional para requerer as perdas da poupança com o Plano Bresser. Jus Navigandi, v. 1447, p. 1-1, 2007. 